\title{
BMJ
}

\section{Place of medical qualification and outcomes of UK General Medical Council "fitness to practise" process: cohort study}

\author{
Charlotte Humphrey, professor of health care evaluation, ${ }^{1}$ Shaista Hickman, research associate, ${ }^{1}$ Martin C \\ Gulliford, professor of public health²
}

${ }^{1}$ Florence Nightingale School of Nursing and Midwifery, King's College London, London SE1 8WA, UK

${ }^{2}$ Department of Primary Care and Public Health Sciences, King's College London, London SE1 3QD

Correspondence to: $\mathrm{C}$ Humphrey charlotte.humphrey@kcl.ac.uk

Cite this as: $B M J$ 2011;340:d1817 doi:10.1136/bmi.d1817

\section{ABSTRACT}

Objectives To evaluate whether country of medical qualification is associated with "higher impact" decisions at different stages of the UK General Medical Council's (GMC's) "fitness to practise" process after allowing for other characteristics of doctors and inquiries.

Design Retrospective cohort study.

Setting Medical practice in the United Kingdom.

Participants 7526 inquiries to the GMC concerning 6954 doctors.

Main outcome measures Proportion of inquiries referred for further investigation at initial triage by the GMC, proportion of inquiries investigated that were subsequently referred for adjudication, and proportion of inquiries resulting in doctors being erased or suspended from the medical register; relative odds of higher impact decisions, by country of qualification, adjusted for doctors' sex, years since primary medical qualification, medical specialty, source and type of inquiry, and nature of allegations.

Results Of 7526 inquiries, 4702 concerned doctors who qualified in the UK, 624 concerned doctors who qualified elsewhere in the European Union (EU), and 2190 concerned doctors who qualified outside the EU. At the initial triage, $30 \%(n=1398)$ of inquiries concerning doctors who qualified in the UK had a high impact decision, compared with $43 \%$ (267) for doctors who qualified elsewhere in the EU and 46\% (998) for those who qualified outside the EU. The adjusted relative odds of an inquiry being referred for further investigation were 1.67 (95\% confidence interval 1.28 to 2.17 ) for doctors who qualified elsewhere in the EU and 1.61 (1.38 to 1.88) for those who qualified outside the EU, compared with doctors who qualified in the UK. At the investigation stage, 5\% (228) of inquiries received concerning UK qualified doctors were referred for adjudication, compared with $10 \%$ for EU (63) or non-EU (221) qualified doctors. The adjusted relative odds of referral for adjudication were 2.14 (1.46 to 3.16) for doctors who qualified elsewhere in the EU and 1.68 (1.31 to 2.16) for those who qualified outside the EU. At the adjudication stage, $1 \%$ (69) of inquiries received concerning UK qualified doctors led to erasure or suspension, compared with $4 \%$ (24) for doctors who qualified elsewhere in the EU and 3\% (71) for non-EU qualified doctors. The adjusted relative odds of erasure or suspension were 2.16 (1.22 to 3.80) for doctors who qualified elsewhere in the EU and 1.48 (1.00 to 2.19) for those who qualified outside the EU. Conclusions Inquiries to the GMC concerning doctors qualified outside the UK are more likely to be associated with higher impact decisions at each stage of the fitness to practice process. These associations were not explained by measured inquiry related and doctor related characteristics, but residual confounding cannot be excluded.

\section{INTRODUCTION}

Migration of health professionals is a matter of growing international concern, with an important loss of human capital for countries of origin. Destination countries may be highly dependent on foreign trained doctors to deliver services in specialties for which shortages exist and in underprovided areas. However, citizens of destination countries are generally concerned to ensure adequate quality and safety in the delivery of services and that cultural differences and communication problems are adequately overcome. Anecdotal reports, and some high profile cases, have suggested that problems may sometimes exist. Foreign trained doctors may themselves encounter difficulties integrating into the health systems of host countries. Studies in the United States and Australia have suggested that foreign trained doctors or those from minority ethnic groups may face discrimination both in the face to face context of clinical work and in organisational arrangements. ${ }^{1-4}$ One qualitative study from the United States described race and ethnicity as "pervasive influences" in the professional lives of doctors of African origins. ${ }^{1}$ Particular concerns have therefore been raised regarding questions of discrimination and fairness in the processes of regulation of medical professionals. ${ }^{4}$ This paper explores the way in which cases involving foreign trained doctors are handled by regulatory processes in the United Kingdom. It does not directly investigate wider questions of potential discrimination in health services or of the quality and safety of medical care. However, these questions provide a wider context in which the study is set.

In the UK, appreciation of the challenges facing foreign trained healthcare staff, irrespective of their ethnic 
status, is growing. ${ }^{5-8}$ At the same time, concerns persist about the effect of racism and discrimination in medicine at many levels. ${ }^{9-15}$

The General Medical Council (GMC) regulates doctors in the UK. Its governing body is made up of both doctors and members of the public. The GMC's functions are assigned by law, as set out in the Medical Act 1983 (www.gmc-uk.org). Its overall purpose is "to protect, promote and maintain the health and safety of the public." Doctors working in the UK must be on the medical register and have a license to practise. The GMC is responsible for administering the register and granting licenses to practise in the UK; it controls entrance to the register and has the power to erase doctors from the register. It is funded by annual fees required from doctors who wish to remain registered and by fees for examinations. It sets educational standards for medical schools and coordinates all stages of medical education. It has powers to advise on standards of professional performance, standards of professional conduct, and medical ethics. The standards of competence, care, and conduct expected of doctors are set out in the GMC's statement of principles, Good Medical Practice. ${ }^{16}$

The GMC has a responsibility to "deal firmly and fairly" with doctors whose fitness to practise is in doubt. It discharges this function through its "fitness to practise" procedures, whereby inquiries of all sorts (including complaints, expressions of concern, or other general questions) received about individual doctors are assessed and investigated, and decisions are made about appropriate action. Such inquiries may come from any source, including individual members of the public, employers' organisations, the police, or other regulatory bodies. The GMC receives and deals with several thousand inquiries each year. All inquiries go through an initial "triage" process to assess whether they raise potential questions about a doctor's fitness to practise. Those that do not are closed or referred back to the doctor's employer for local investigation. The minority that do raise concerns about impaired fitness to practise - through deficient performance, misconduct, criminal behaviour, or physical or mental ill health-are taken forward to the next stage of "investigation" by the GMC. The investigation may include obtaining additional documentary evidence, witness statements, or expert reports and assessing the doctor's performance or health. Once investigations are completed, cases are reassessed by both medical and non-medical case examiners. Most cases are concluded at this stage without further action. Some doctors receive a warning, and some are asked to agree specific undertakings about their future practice. Some cases are referred to a fitness to practise panel hearing. This is the final "adjudication" stage of the procedures, in which a group of specially trained medical and non-medical members hear all the evidence in public and decide what action, if any, is needed. In the most serious cases, the panel may decide to erase or suspend a doctor's registration. Doctors who are subject to investigation or action by the GMC are encouraged to obtain legal representation and advice from medical defence organisations or other professional associations or by private arrangement, and they have the right to appeal decisions.

Awareness of possible inequalities and unfairness within the GMC's fitness to practise procedures has existed for some time in respect of both doctors from ethnic minorities and non-UK qualified doctors (that is, those who received their primary medical training and degree in other countries). Concerns about the volume of doctors from ethnic minorities involved in these procedures, and the possibility of racism, first emerged in the early $1990 \mathrm{~s} .{ }^{17}$ A subsequent investigation by the Policy Studies Institute of the GMC's handling of complaints found that the proportion of non-UK qualified doctors who were the subject of complaints to the GMC was consistent with their presence in the overall population of doctors working in the UK. ${ }^{18}$ However, differences existed between the non-UK qualified and UK qualified doctors dealt with by the GMC. Non-UK qualified doctors were older and included more general practitioners, and disproportionately more of the complaints about them came from public bodies than from other sources. The Policy Studies Institute's study also noted that complaints received from public bodies were more likely to progress to later stages of GMC procedures than were those from other sources. These various differences might help to explain the finding that non-UK qualified doctors were over-represented, compared with UK qualified doctors, at later stages. An unpublished analysis by the York Health Economics Consortium broadly confirmed these findings.

Limitations in quality of data in these earlier studies precluded the possibility of doing multivariable analyses to investigate the independent associations of ethnicity or country of qualification, after adjustment for other doctor related or inquiry related characteristics, with progress within the fitness to practise process. A continuing tendency equates "coming from abroad" with ethnic minority status when people speculate about possible discrimination in patterns of medical regulatory risk. ${ }^{1920}$ Meanwhile, the GMC has responded to these concerns by collecting information on doctors' ethnicity, as well as publishing outcomes of the fitness to practise process by ethnic group. ${ }^{21}$

In the light of the increasing focus at national level on equality and fairness in professional regulatory procedures, ${ }^{22}$ a need remains to better understand both migration and ethnicity related patterns of medical regulatory risk. The quality of the data that documents the fitness to practise processes has much improved since the GMC's introduction of a new data management system in 2005. Recent efforts to obtain better self reported information about doctors' ethnicity means that the GMC now holds such information for most doctors on the medical register. Taking advantage of the opportunities presented by these new developments, we did a new analysis. We aimed to test the hypotheses that non-UK qualified doctors are more likely to receive "high impact" decisions at each 
stage of the fitness to practise process independent of other demographic or professional factors or characteristics of the complaints received.

\section{METHODS}

\section{Study design}

The GMC holds basic demographic and professional data for all doctors on the medical register, including information about country of qualification and nationality (confirmed by documentary evidence presented by the doctor at the point of applying to join the register). When the GMC receives an inquiry about a doctor, some additional information is collected about the doctor's employment and the source and nature of the inquiry. Progress through the fitness to practise procedures and decisions on final outcomes are also recorded on the database. The GMC has audit processes to monitor and maintain the quality of data and uses exception reporting on a regular cycle to pick up anomalies in data. This research used doctor related and inquiry related data for a cohort comprising all inquiries about registered doctors received between 1 April 2006 and 31 March 2008. The start date was the earliest feasible one after the introduction of the new management database in 2005; the end date allowed at least a year for cases to have been investigated by the GMC before the dataset was extracted for analysis in April 2009. GMC staff extracted the data, anonymised it by removing variables containing individual identifiers (doctor's name, registration number), and supplied the full set to us on Excel spreadsheets. Two members of the research team checked and cleaned the data; some variables with many values, such as country of qualification, year of qualification, and self reported ethnicity, were simplified for analysis.

We used these data to investigate decisions made at three consecutive stages in the fitness to practise procedures: the initial triage, the following investigation, and adjudication. The figure shows the sequential structure of these procedures. We grouped outcomes at each stage according to the seriousness of their implications for the doctor concerned. The main outcomes of interest were the "high impact" decisions at each of the three decision points.

We selected inquiries, rather than doctors, as the unit of analysis because one doctor may be the subject of more than one inquiry and each might be associated with a different outcome. All inquiries received during the two year study period were eligible for analysis. However, we excluded "restoration applications," involving requests from doctors who had previously been erased from the medical register for their registration to be restored, because they are dealt with separately from the main fitness to practise process.

\section{Variables included in analysis}

The main predictors of interest were doctors' country of qualification and self reported ethnicity. We analysed country of primary medical qualification by using the categories United Kingdom; elsewhere in the European Union or European Economic Area (EU); and outside the United Kingdom, European Union, or European Economic Area (non-EU). Self reported data for doctors' ethnicity were available for $64 \%(4784 / 7526)$ of all inquiries in the dataset. However, ethnicity data were available for 59\% (1574/ 2663) of inquiries that progressed to further investigation, 54\% (278/512) of those referred for adjudication, and $43 \%(70 / 164)$ of those that resulted in erasure or suspension. We reduced self reported ethnicity to the categories of confirmed "white" and confirmed "black and minority ethnic."

We adjusted analyses for six potentially confounding variables. These included three inquiry related variables: inquiry source (member of the public, public organisation, person acting in a public capacity, other doctor), inquiry type (complaint, referral, criminal conviction, determination), and inquiry content. An inquiry to the GMC may contain allegations or concerns about one or several aspects of a doctor's practice, conduct, or circumstances (clinical care, relationships with patients, working with colleagues, problems of probity, or problems with the doctor's own health), and a separate record exists on the database for each allegation. We evaluated the content of inquiries by using the presence or absence within the inquiry of each different type of allegation. Doctor related variables were sex, time since primary medical qualification, and a simple breakdown of specialty (general practitioner/not general practitioner). Six inquiries had missing general practitioner status, which we classified as "other specialties." Eight inquiries had missing inquiry source, which we classified as "other source." Ten inquiries had missing country of qualification, which we included as a separate category for analysis but omitted from the tables. Other potentially relevant items in the database included doctor's age, a more detailed breakdown of specialty, qualifications, employment status, and employment sector. However, the data on these items were too incomplete for us to include them in the analysis.

\section{Analysis}

The analysis presented several methodological difficulties. The data included 400 observations without final decisions recorded at the time of data extraction. We treated these cases as a separate category of outcome. Outcomes were recorded at three decision points, but outcomes at later decision points were conditional on earlier decisions. For this analysis, we modelled outcomes separately for the three decision points - triage, investigation, and adjudication. At each decision point, we fitted a multinomial logistic model with the decision outcome as the dependent variable. This had the categories "high impact" outcome, "intermediate impact" outcome, "low impact" outcome, and no decision yet. At the investigation and adjudication decision points, we classified observations that were associated with low or intermediate impact outcomes at the earlier decision points, and which therefore did not progress to the later decision point, as 


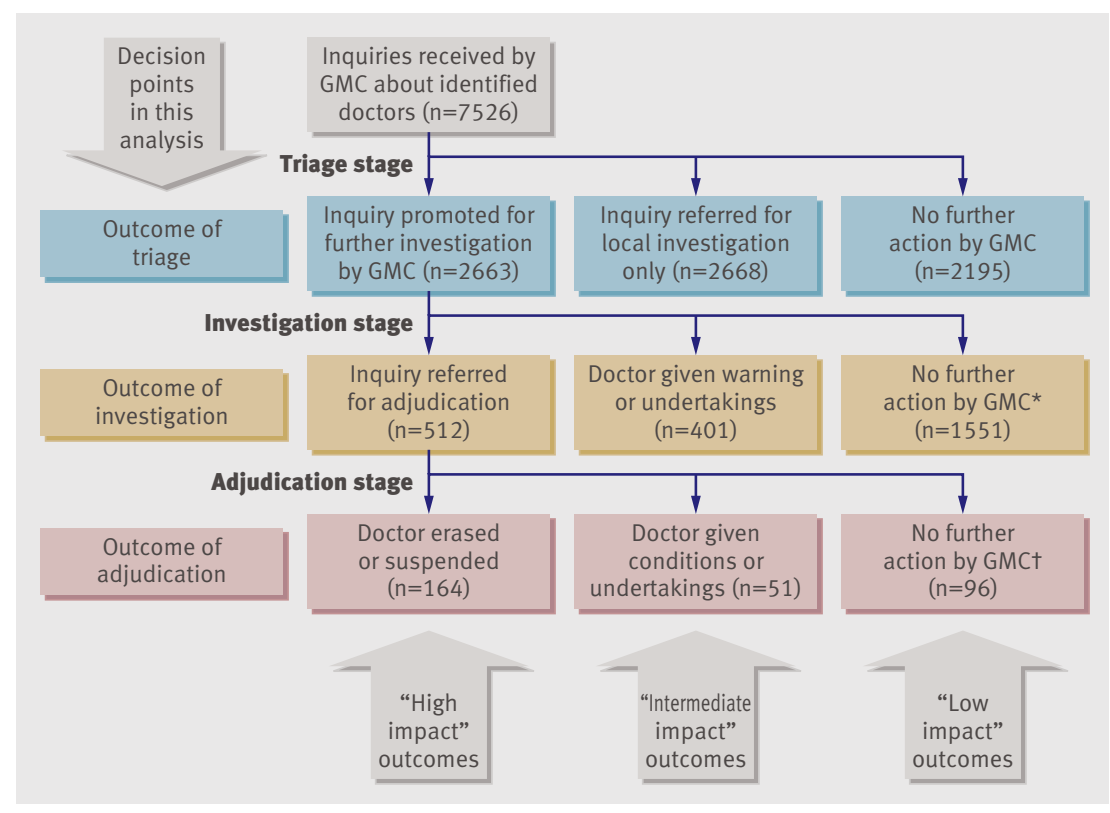

Flow chart showing progression of inquiries through GMC fitness to practise procedures. ${ }^{*} 199$ with no decision yet. $† 201$ with no decision yet

having low impact decisions at the later decision point. This allowed all observations to be included in the analysis for each decision point. As a sensitivity analysis, we evaluated outcomes for those inquiries that were referred for further investigation at the triage stage. We estimated odds ratios for high impact outcomes at each decision point for each variable listed, using the low impact category "closed, no further action" for reference.

Explanatory variables included were sex, country of qualification (grouped as UK, rest of European Union and European Economic Area, and outside this area), years since qualification, doctor's specialty, inquiry type, inquiry source, and (in selected models) content of inquiry. We did not include content of inquiry at the investigation stage, because allegations are not entered on the GMC database for inquiries that are closed at triage. We used the robust option to allow for clustering of inquiry outcomes by doctor. We explored whether ethnicity was an effect modifier by testing for interactions and comparing outcomes for non-UK trained doctors after stratifying by ethnic group.

\section{Sample size calculation}

We anticipated a sample of 8000 inquiries, including 2000 concerning doctors qualified outside the UK. If $40 \%$ of those inquiries received high impact decisions at triage, we would have more than $90 \%$ power to detect a difference in proportion of such decisions between groups of about $4.5 \%$. If 600 cases (including 200 concerning doctors qualified outside the UK) progressed through the process as far as a fitness to practise panel hearing, and $50 \%$ of those cases received high impact decisions at adjudication, then we would have more than $90 \%$ power to detect a difference in proportion of unfavourable decisions between groups of $15 \%$.

\section{RESULTS}

Sample characteristics

We had 12246 records of allegations available for analysis. We excluded one record with missing information on sex and 123 records because they were restoration applications. We then had 12122 records remaining. We grouped records for allegations relating to the same doctor, received on the same date, and allocated to the same route at triage and treated them as a single inquiry. This process identified 7526 inquiries, involving 6954 doctors.

Of the 7526 inquiries, 2663 (35\%) were referred for further investigation by the GMC, $512(7 \%)$ were subsequently referred for adjudication, and $164(2 \%)$ resulted in erasure or suspension of the doctor concerned. Four hundred inquiries had reached no final outcome by April 2009 when the dataset was extracted (199 of these were still awaiting a decision following investigation, and 201 were awaiting the outcome of adjudication). The figure shows a flow chart.

Table 1 gives descriptive statistics for the 7526 inquiries. Comparisons can be made with NHS workforce data on the general population of doctors employed in the NHS in $2008^{23}: 80 \%$ of the inquiries involved male doctors, whereas only $58 \%$ of doctors employed in the NHS were male; $46 \%$ of the inquiries involved doctors in general practice, whereas only $28 \%$ of doctors employed in the NHS were general practitioners; $62 \%$ of the inquiries involved doctors qualified for more than 20 years, whereas only $39 \%$ of doctors employed in the NHS were older than 45 (and therefore likely to have been qualified that long); and 37\% of the inquiries involved non-UK qualified doctors, whereas only $33 \%$ of doctors employed in the NHS had been trained in other countries.

Within the cohort of inquiries, modest differences by place of qualification existed for doctor related variables: more of those qualified outside the EU were male, more of those qualified elsewhere in the EU had qualified in the previous 20 years, and more of the UK qualifiers were general practitioners. Variations also existed with regard to the inquiry related variables: more of the inquiries about UK qualifiers came from individual members of the public, whereas more of those concerning non-UK qualified doctors came from organisational sources; more of the inquiries about UK qualifiers were categorised as "complaints," whereas more of those involving non-UK qualified doctors were defined as "referrals;" and marginally more inquiries involving doctors qualified outside the EU included allegations concerning "probity."

\section{Associations with "higher impact" outcomes}

Table 2 shows the pattern of progression, and outcomes, of the fitness to practise process at the triage, investigation, and adjudication stages. At the triage stage, referral for investigation was more frequent for inquiries involving non-UK qualified doctors, including both EU and non-EU qualified doctors (table 2). At the initial triage, $30 \%$ of inquiries concerning UK qualified doctors had a high impact decision, compared 
Table 1 |Characteristics of cohort of inquiries, according to country of qualification. Values are frequencies (column percentages)

\begin{tabular}{|c|c|c|c|c|}
\hline & $\begin{array}{l}\text { Qualified in UK } \\
(n=4702)\end{array}$ & $\begin{array}{l}\text { Qualified elsewhere } \\
\text { in EU/EEA }(n=624)\end{array}$ & $\begin{array}{l}\text { Qualified outside } \\
\text { EU/EEA }(n=2190)\end{array}$ & $\begin{array}{c}\text { Total* } \\
(n=7526)\end{array}$ \\
\hline \multicolumn{5}{|l|}{ Ethnicity } \\
\hline Known "white" & $2648(56)$ & $283(45)$ & $205(9)$ & $3136(42)$ \\
\hline Known "black and minority ethnic" & $408(9)$ & $62(10)$ & $1168(53)$ & $1638(22)$ \\
\hline Ethnicity not known & $1646(35)$ & $279(45)$ & $817(37)$ & $2752(37)$ \\
\hline \multicolumn{5}{|l|}{ Sex } \\
\hline Male & $3666(78)$ & $479(77)$ & $1832(84)$ & $5985(80)$ \\
\hline Female & $1036(22)$ & $145(23)$ & $358(16)$ & $1541(20)$ \\
\hline \multicolumn{5}{|l|}{ Years since qualification } \\
\hline$\leq 10$ & $586(12)$ & $97(16)$ & 291 (13) & 974 (13) \\
\hline 11 to 20 & $1137(24)$ & 245 (39) & $493(23)$ & $1875(25)$ \\
\hline 21 to 30 & $1686(36)$ & $189(30)$ & $515(24)$ & $2392(32)$ \\
\hline 30 to 40 & $1051(22)$ & 79 (13) & $677(31)$ & $1808(24)$ \\
\hline$>40$ & $241(5)$ & $14(2)$ & $211(10)$ & $468(6)$ \\
\hline Not known & $1(0)$ & $0(0)$ & $3(0)$ & $9(0)$ \\
\hline \multicolumn{5}{|l|}{ Specialty } \\
\hline General practice & $2270(48)$ & $268(43)$ & $923(42)$ & $3461(46)$ \\
\hline Other specialties & $2432(52)$ & $356(57)$ & $1267(58)$ & $4065(54)$ \\
\hline \multicolumn{5}{|l|}{ Source of inquiry } \\
\hline Public (individual) & $3406(72)$ & $329(53)$ & $1241(57)$ & $4980(66)$ \\
\hline Public (organisation) & $451(10)$ & 107 (17) & 377 (17) & $937(12)$ \\
\hline Person acting in a public capacity & $343(7)$ & $125(20)$ & $335(15)$ & $807(11)$ \\
\hline Other doctor & $412(9)$ & $52(8)$ & $199(9)$ & $663(9)$ \\
\hline Other source & $90(2)$ & $11(2)$ & $38(2)$ & $139(2)$ \\
\hline \multicolumn{5}{|l|}{ Type of inquiry } \\
\hline Complaint & $3935(84)$ & 397 (63) & $1496(68)$ & $5832(77)$ \\
\hline Referral & $357(8)$ & $117(19)$ & $436(20)$ & $910(12)$ \\
\hline Criminal conviction $†$ & $276(6)$ & $36(6)$ & $166(8)$ & $483(6)$ \\
\hline Determination $\ddagger$ & $19(0)$ & $11(2)$ & $19(1)$ & $49(1)$ \\
\hline Other & $115(2)$ & $63(10)$ & $73(3)$ & $252(3)$ \\
\hline \multicolumn{5}{|l|}{ Content of inquiry§ } \\
\hline Clinical care & $1981(42)$ & $258(41)$ & $926(42)$ & $3165(42)$ \\
\hline Probity & $676(14)$ & $93(15)$ & $423(19)$ & $1192(16)$ \\
\hline Relationships with patients & $689(15)$ & $87(14)$ & $316(14)$ & $1092(15)$ \\
\hline Working with colleagues & $170(4)$ & $30(5)$ & $109(5)$ & $309(4)$ \\
\hline Doctor's health & $188(4)$ & $18(3)$ & $76(4)$ & $282(4)$ \\
\hline \multicolumn{5}{|c|}{$\begin{array}{l}\text { EEA=European Economic Area; EU=European Union. } \\
\text { *Data for } 10 \text { inquiries with missing country of qualification are not shown. } \\
\text { †Conviction or caution in British Isles for criminal offence or conviction elsewhere for offence which, if committed in England or Wales, would } \\
\text { constitute criminal offence. } \\
\text { †Determination by body in UK responsible under any enactment for regulation of healthcare or social care profession to effect that his/her fitness to } \\
\text { practise as member of that profession is impaired, or determination by regulatory body elsewhere to same effect. } \\
\text { §Inquiries may be associated with several categories of allegation; allegations were not recorded/analysed for inquiries that were closed at initial } \\
\text { triage. }\end{array}$} \\
\hline
\end{tabular}

with $43 \%$ for doctors who qualified elsewhere in the EU and $46 \%$ for non-EU qualified doctors. Investigation was more frequent for male doctors, inquiries received from all sources other than individual members of the public, and inquiries categorised as "referral" or "criminal conviction"). Adjustment for case mix did not account for the association between country of qualification and outcome of triage. The adjusted relative odds of an inquiry being referred for further investigation, compared with UK qualified doctors, were 1.67 (95\% confidence interval 1.28 to 2.17 ) for doctors who qualified elsewhere in the EU and 1.61 (1.38 to 1.88) for those who qualified outside the EU.
At the investigation stage, referral for adjudication was more frequent for inquiries involving non-UK qualified doctors (both EU and non-EU) (table 2). At this stage, $5 \%$ of all inquiries received concerning UK qualified doctors were referred for adjudication, compared with $10 \%$ for EU or non-EU qualified doctors. Inquiries concerning male doctors; those received from all sources other than individual members of the public; inquiries categorised as "referral," "criminal conviction," or "determination;" and inquiries including allegations about clinical care, probity, relationships with patients, working with colleagues, or doctor's health were also more likely to be referred 
for adjudication. In the adjusted model, the adjusted relative odds of referral for adjudication, compared with UK qualified doctors, were 2.14 (1.46 to 3.16 ) for doctors who qualified elsewhere in the $\mathrm{EU}$ and 1.68 (1.31 to 2.16 ) for those who qualified outside the EU. When we restricted the model to the 2663 participants who were referred for investigation at the triage stage, the adjusted odds ratio for doctors qualified outside the $\mathrm{EU}$ was 1.49 (1.16 to $1.92 ; \mathrm{P}=0.002$ ).

At the adjudication stage, erasure or suspension was more frequent for inquiries involving non-UK qualified doctors (EU/EEA and, to a lesser extent, outside EEA) (table 2). At this stage, $1 \%$ of all inquiries received concerning UK qualified doctors led to erasure or suspension compared with $4 \%$ for EU qualified doctors and 3\% for non-EU qualified doctors. High impact decisions were more frequent for inquiries received from organisational sources; inquiries categorised as "referral" or "determination;" and inquiries including allegations about probity, relationships with patients, or doctor's health. The adjusted relative odds of erasure or suspension, compared with UK qualified doctors, were 2.16 (1.22 to 3.80) for doctors who qualified elsewhere in the EU and 1.48 (1.00 to 2.19) for those who qualified outside the EU. When we restricted the model to the 2663 participants who were referred for investigation at the triage stage, the adjusted odds ratio for erasure or suspension of doctors who qualified outside the EU was 1.48 (1.02 to 2.16; $\mathrm{P}=0.040$ ). However, we did not adjust this analysis for inquiry type because of problems of non-convergence. When we restricted the model to the 512 inquiries referred for adjudication, odds ratios were similar but associations were not statistically significant.

Inquiries concerning UK qualified doctors included 2648 with known "white" ethnicity and 408 with known "black and minority ethnic" ethnicity; 488 inquiries were associated with non-UK qualified doctors of white ethnicity, and 1230 inquiries concerned non-UK qualified black and minority ethnic doctors (table 1); the remainder were of unknown ethnicity. We explored whether associations of country of qualification with GMC outcomes differed by ethnic group. Interaction terms between country of qualification and ethnicity were not significant at the triage and investigation stages. At the adjudication stage, the interaction term was significant owing to a strong association of higher impact decisions with "not known" ethnicity. Table 3 shows the adjusted odds ratios at triage, investigation, and adjudication by subgroups of confirmed ethnicity and place of qualification. Categories for UK qualified doctors of "not known" ethnicity (1646 inquiries), non-UK qualified doctors of "not known" ethnicity (1096 inquiries), and doctors of "not known" country of qualification and ethnicity (10 inquiries) are not shown but were included in regression models. Inquiries concerning UK qualified doctors showed no association between ethnicity and decision outcome at any stage of the process. Inquiries involving non-UK qualified doctors, including both white and black and minority ethnic groups, were associated with high impact outcomes at the triage and investigation stages. Among non-UK qualified doctors, in adjusted analyses outcomes were generally similar for those whose

\begin{tabular}{|c|c|c|c|c|c|c|c|}
\hline Stage of process & Total & Low impact outcome & $\begin{array}{l}\text { Intermediate } \\
\text { impact outcome }\end{array}$ & $\begin{array}{l}\text { High impact } \\
\text { outcome }\end{array}$ & No decision yet & $\begin{array}{c}\text { Adjusted odds ratio* } \\
(95 \% \mathrm{Cl})\end{array}$ & $P$ value \\
\hline Outcome of initial triage†: & & No further action & Local investigation & $\begin{array}{l}\text { Referred for further } \\
\text { investigation }\end{array}$ & & & \\
\hline All inquiries & 7526 & 2195 & 2668 & 2663 & & & \\
\hline UK qualified & 4702 & $1484(32)$ & $1820(39)$ & $1398(30)$ & & Reference & \\
\hline Rest of EU/EEA qualified & 624 & $180(29)$ & $177(28)$ & $267(43)$ & & 1.67 (1.28 to 2.17$)$ & $<0.001$ \\
\hline Outside EU/EEA qualified & 2190 & $521(24)$ & $671(31)$ & $998(46)$ & & 1.61 (1.38 to 1.88$)$ & $<0.001$ \\
\hline Outcome of investigation†ł: & & No further action & $\begin{array}{l}\text { Warnings or } \\
\text { undertakings }\end{array}$ & $\begin{array}{l}\text { Referred for } \\
\text { adjudication }\end{array}$ & & & \\
\hline All inquiries & 7526 & 6414 & 401 & 512 & 199 & & \\
\hline UK qualified & 4702 & 4174 (89) & $219(5)$ & $228(5)$ & $81(2)$ & Reference & \\
\hline Rest of EU/EEA qualified & 624 & 496 (79) & $39(6)$ & $63(10)$ & $26(4)$ & 2.14 (1.46 to 3.16$)$ & $<0.001$ \\
\hline Outside EU/EEA qualified & 2190 & 1734 (79) & $143(7)$ & $221(10)$ & $92(4)$ & 1.68 (1.31 to 2.16$)$ & $<0.001$ \\
\hline Outcome of adjudicationt§: & & No further action & $\begin{array}{l}\text { Conditions or } \\
\text { undertakings }\end{array}$ & $\begin{array}{c}\text { Erasure or } \\
\text { suspension }\end{array}$ & & & \\
\hline All inquiries & & 7110 & 51 & 164 & 201 & & \\
\hline UK qualified & 4702 & $4522(96)$ & $29(1)$ & 69 (1) & $82(2)$ & Reference & \\
\hline Rest of EU/EEA qualified & 624 & $571(92)$ & $6(1)$ & $24(4)$ & $23(4)$ & $2.16(1.22$ to 3.80$)$ & 0.008 \\
\hline Outside EU/EEA qualified & 2190 & 2007 (92) & $16(1)$ & $71(3)$ & $96(4)$ & 1.48 (1.00 to 2.19$)$ & 0.049 \\
\hline
\end{tabular}

EEA=European Economic Area; EU=European Union.

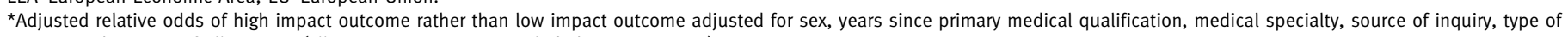
inquiry, and content of allegations (allegation type was not included at triage stage).

tData for 10 inquiries with missing country of qualification are not shown.

$\ddagger$ Participants who were not referred for investigation were included as having low impact outcome.

§Participants who were not referred for adjudication were included as having low impact outcome. 
Table 3| Outcomes at each stage by place of qualification and ethnic group. Values are frequencies (row percentages) unless stated otherwise

\begin{tabular}{|c|c|c|c|c|c|c|c|}
\hline Stage of process & All* & $\begin{array}{l}\text { Low impact } \\
\text { outcome }\end{array}$ & $\begin{array}{l}\text { Intermediate impact } \\
\text { outcome }\end{array}$ & $\begin{array}{l}\text { High impact } \\
\text { outcome }\end{array}$ & No decision yet & $\begin{array}{l}\text { Adjusted odds ratio } † \\
(95 \% \mathrm{Cl})\end{array}$ & $P$ value \\
\hline Outcome of triage: & & No further action & $\begin{array}{c}\text { Local investigation } \\
\text { only }\end{array}$ & $\begin{array}{l}\text { Referred for } \\
\text { investigation }\end{array}$ & & & \\
\hline UK qualified, confirmed "white" & 2648 & $874(33)$ & $1086(41)$ & $688(26)$ & - & Reference & \\
\hline UK qualified, confirmed "BME" & 408 & $111(27)$ & $150(37)$ & $147(36)$ & - & $1.29(0.95$ to 1.75$)$ & 0.100 \\
\hline Not UK qualified, confirmed "white" & 488 & $135(28)$ & $161(33)$ & $192(39)$ & - & $1.64(1.23$ to 2.20$)$ & $<0.001$ \\
\hline Not UK qualified, confirmed "BME" & 1230 & $280(23)$ & $403(33)$ & $547(44)$ & - & $1.88(1.53$ to 2.31$)$ & $<0.001$ \\
\hline Outcome of investigation: & & No further action & $\begin{array}{l}\text { Warnings or } \\
\text { undertakings }\end{array}$ & $\begin{array}{l}\text { Referred for } \\
\text { adjudication }\end{array}$ & & & \\
\hline UK qualified, confirmed "white" & 2648 & $2414(91)$ & $98(4)$ & $97(4)$ & $39(1)$ & Reference & \\
\hline UK qualified, confirmed "BME" & 408 & $345(85)$ & $31(8)$ & $22(5)$ & $10(2)$ & $1.26(0.74$ to 2.15$)$ & 0.386 \\
\hline Not UK qualified, confirmed "white" & 488 & $410(84)$ & $26(5)$ & $33(7)$ & $19(4)$ & 1.78 (1.10 to 2.87$)$ & 0.019 \\
\hline Not UK qualified, confirmed "BME" & 1230 & $972(79)$ & $96(8)$ & $126(10)$ & $36(3)$ & 2.35 (1.67 to 3.30$)$ & $<0.001$ \\
\hline Outcome of adjudication: & & No further action & $\begin{array}{l}\text { Conditions or } \\
\text { undertakings }\end{array}$ & $\begin{array}{c}\text { Erasure or } \\
\text { suspension }\end{array}$ & & & \\
\hline UK qualified, confirmed "white" & 2648 & $2577(97)$ & $8(<1)$ & $22(1)$ & $41(2)$ & Reference & \\
\hline UK qualified, confirmed "BME" & 408 & $388(95)$ & $2(<1)$ & $8(2)$ & $10(2)$ & $1.80(0.70$ to 4.67$)$ & 0.225 \\
\hline Not UK qualified, confirmed "white" & 488 & $461(94)$ & $6(1)$ & $10(2)$ & $11(2)$ & $1.95(0.86$ to 4.44$)$ & 0.111 \\
\hline Not UK qualified, confirmed "BME" & 1230 & $1125(91)$ & $12(1)$ & $30(2)$ & $63(5)$ & 1.84 (1.00 to 3.40$)$ & 0.051 \\
\hline
\end{tabular}

BME=black and minority ethnic.

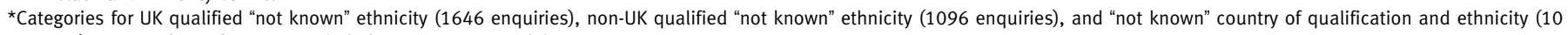
inquiries) are not shown but were included in regression models.

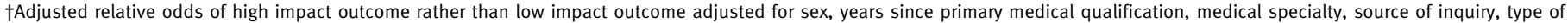
inquiry, and content of allegations (allegation type was not included at triage stage).

ethnicity was white or black and minority ethnic. At the adjudication stage, we found only small numbers of high impact decisions when data were disaggregated by ethnicity and country of qualification.

\section{DISCUSSION}

These analyses suggest that non-UK qualified doctors are more likely to receive "high impact" decisions at each stage of the General Medical Council's fitness to practise process. This association is partially explained, but cannot be fully accounted for, by confounding with other inquiry related and doctor related characteristics that are themselves associated with high impact outcomes. The results point to two different potential explanations for the findings of this study. One explanation might be that real differences exist in fitness to practise between groups of doctors who are referred to the GMC, even when measured inquiry related characteristics have been taken into account. A second potential explanation is that the GMC processes tend to discriminate against certain groups of doctors. However, we caution that several limitations of the data make it difficult to reach a conclusion that clearly supports either of these potential explanations, and both might be valid.

\section{Strengths and weaknesses of study}

The GMC's new database and the GMC's ethnicity survey have between them generated substantial improvements in the quality of data on the fitness to practise process. Nevertheless, this was a secondary analysis of data routinely collected and kept by the GMC for internal management purposes. The main limitations we encountered were as follows. The size of this study was constrained by the number of inquiries received by the GMC since the improved database was introduced, and the number of high impact outcomes at the adjudication stage was relatively small. Four hundred inquiries had not reached a final outcome at the time the dataset was extracted. The achieved sample size was consistent with expectations; 7526 inquiries were analysed (8000 anticipated) and 512 referred for adjudication (600 anticipated). At the triage stage, the absolute difference between UK qualified and non-EU qualified groups was $17 \%$, considerably greater than the smallest difference expected. At the adjudication stage, small numbers of cases had high impact decisions and the study did not have sufficient power to detect small effects that might nevertheless be considered important. Hypotheses were tested at each stage of the fitness to practise process, but we did not adjust for multiple testing. We note that adjusted analyses were reported on the odds ratio scale, whereas sample size calculations were implemented using proportions.

We were constrained by the variables available for analysis and by the quality and completeness of the data within them. Importantly, the data available on ethnicity were incomplete and the proportion of missing values was associated with fitness to practise outcomes. Findings with respect to ethnicity must be interpreted cautiously. Different results might be obtained if ethnicity data were available for all doctors. The GMC's survey of doctors on the UK medical register that requested information about ethnicity took place in the winter of 2007-8, which was towards the end of the period covered by our dataset. Most of the doctors in our sample will therefore have received that 
request during or soon after their involvement with the fitness to practise process, and that those who had progressed further through the process were less likely to comply is perhaps not surprising. Coverage of ethnicity data has improved since this study was completed, and this improvement will continue as new doctors join the register. ${ }^{21}$ Differences may exist between ethnic groups that were concealed by the broad categorisation used in this paper. However, the small number of outcomes at the adjudication stage limited the potential for a more fine grained analysis by ethnic group. Doctors' practice was divided into the broad categories of "specialist" and "general practitioner." Different specialties probably include varying proportions of foreign trained doctors and have different risks of referral to the GMC. However, a more detailed evaluation of specialty would require larger numbers of cases for analysis. Information on whether English was a first language was not available for analysis.

A further limitation of the data was the limited information available on the nature and severity of the complaints against individual doctors. We analysed data on source of inquiry, type of inquiry, and broad categories of complaint. However, residual confounding might occur if systematic differences exist in the seriousness of alleged offences between groups, even after adjustment for inquiry related characteristics. This form of potential bias is difficult to overcome in a non-randomised study. A detailed qualitative examination of the details of individual cases might be needed to explore whether differences in outcomes observed here might be explained by differences in the types of alleged offences that were the cause of initial complaints.

\section{Strengths and weaknesses in relation to other studies}

These data are consistent with unadjusted data reported by the GMC for $2009 .^{24}$ The GMC reported that $60 \%$ of all inquiries in 2009 concerned doctors who qualified in the UK, 10\% were for doctors who trained in the European Economic Area, and 30\% were for doctors who trained outside this area. The proportions of all registered doctors falling into these categories were $63 \%, 9 \%$, and $28 \%{ }^{24}$ This suggests that the breakdown of all inquiries by country of qualification is broadly consistent with the distribution of doctors. The earlier studies of the fitness to practise process done by the Policy Studies Institute and the York Health Economics Consortium found that several doctor related variables, including sex, age, specialty, and place of qualification, were linked to the overall risk of referral to the GMC, as well as to the source of referral and likelihood of progression to later stages of the fitness to practise process. ${ }^{18}$ Recent analyses of NHS referrals to the National Clinical Assessment Service (NCAS) about doctors whose performance is giving cause for concern have found similar patterns in the overall profile of regulatory referral. ${ }^{25}$ Our analysis confirmed these associations but went further than the other studies by adjusting for confounding variables. Our study thereby adds new understanding of the relative importance of the various apparent sources of risk. Moreover, by using the derived variable combining "confirmed" ethnicity and country of qualification, we have been able for the first time to investigate the possible associations of these two factors in different combinations. The recent NCAS report also attempts some analysis of referrals to its services by ethnicity and place of qualification considered separately. ${ }^{25}$ The NCAS findings show a greater risk of referral for non-white, non-UK qualified doctors but give no indication of disproportionately higher referral rates among non-white UK qualified doctors.

\section{Meaning of study}

If the GMC's fitness to practise process is working effectively, the decisions made within it should be influenced primarily by consideration of the nature and content of the allegations and not by unrelated characteristics of the doctor or doctors involved. The fact that the inquiry related variables were strong predictors of outcomes in this study provides some reassurance that the system is functioning as intended. The finding of an increased risk for non-UK qualified doctors (and for male doctors at earlier stages in the process), which is not fully accounted for by adjustment for inquiry related variables, raises questions about the role of other influences. One possibility is that more subtle differences of substance or presentation exist between inquiries involving UK qualified and nonUK qualified doctors than were manifest in the broadbrush categorisations of inquiries that we used for this analysis. Another possibility is that inquiries involving UK qualified doctors are assessed as being in some way "less serious" than those involving a non-UK qualified doctor with the same inquiry details. Against this suggestion, we note that an independent audit of recorded documentation about decisions on fitness to practise taken at the request of the GMC in 2007 by a team involving one of the authors $(\mathrm{CH})$ found no evidence of assessment criteria being inconsistently applied. However, the audit involved no direct observation of decision making processes or consideration of any unintended biases that may be embedded with the assessment criteria themselves. A further possibility might be that some non-UK qualified doctors may be less well placed than those trained in the UK to defend themselves or challenge decisions, perhaps because of fewer resources and connections or less confidence or external support. Subgroups of countries or regions of qualification may exist that have either higher or lower risk of negative outcomes in the fitness to practise process. However, in the absence of prior hypotheses we did not explore this possibility.

We did not have information on the ethnicity or country of origins of people who were engaged in implementing the fitness to practise processes. Implementation of fitness to practise processes "blinding" the ethnicity or country of qualification of doctors is not feasible. However, the GMC implements processes that aim to minimise the risk of bias through routine internal auditing of decisions. 


\section{WHAT IS ALREADY KNOWN ON THIS TOPIC}

Doctors who qualified outside the UK have been shown to be over-represented, compared with UK qualified doctors, at later stages of the fitness to practise process

However, this might be explained by confounding by factors related to the doctor or the complaint

\section{WHAT THIS STUDY ADDS}

Non-UK qualified doctors are more likely to receive "high impact" decisions at each stage of the fitness to practise process

This association is not explained by other measured complaint related and doctor related characteristics
Ethical approval: Ethical approval for the study was granted by the King's College London Research Ethics Committee on 31 July 2008.

Data sharing: No additional data available.

1 Nunez-Smith M, Curry LA, Bigby J, Berg D, Krumholz HM, Bradley EH. Impact of race on the professional lives of physicians of African descent. Ann Intern Med 2007;146:45-51.

2 Chen PG, Nunez-Smith M, Bernheim SM, Berg D, Gozu A, Curry LA. Professional experiences of international medical graduates practicing primary care in the United States. J Gen Intern Med 2010;25:947-53.

3 Louis WR, Lalonde RN, Esses VM. Bias against foreign-born or foreign-trained doctors: experimental evidence. Med Educ 2010;44:1241-7.

4 Moynihan R. Australia launches inquiry into treatment of overseas trained doctors. BMJ 2010;341:c6780.

5 Roberts C, Sarangi S, Southgate L, Wakeford R, Wass L. Oral examinations-equal opportunities, ethnicity, and fairness in the MRCGP. BMJ 2000;320:370-5.

NHS organisations play a role in the regulation of doctors' practice through the appraisal process. Primary care trusts also discharge responsibilities in respect of underperforming doctors. Concerns may be resolved at the local level but might lead to referral to the GMC. Different thresholds might be used for referral for UK trained compared with foreign trained doctors. However, we could not explore this possibility with data used for this study.

\section{Unanswered questions and future research}

Our study adds insights into the importance of place of qualification in relation to the fitness to practise arrangements for regulating medical professionals. Understanding of possible reasons behind the increased risk of "high impact" outcomes for non-UK qualified doctors might be enhanced by more detailed, qualitative investigations looking at how decisions are made about the categorisation and handling of inquiries, how the detailed content of allegations may vary between different groups of doctors, and the experiences of doctors themselves as they go through the fitness to practise process.

We thank Aneez Esmail, Debbie Cohen, James Nazroo, Celia Davies, and Celia Roberts for their valuable comments and feedback during oral presentations of the data. We are grateful to staff at the GMC who assisted our access to the fitness to practise data.

Contributors: $\mathrm{CH}$ and MCG were responsible for the conception and design of the study. SH and MCG did the statistical analysis of data. All authors had full access to all of the data and can take responsibility for its integrity and the accuracy of the analysis. CH, MCG, and SH drafted the manuscript and completed critical revisions. All authors approved the final manuscript. $\mathrm{CH}$ and MCG are the guarantors.

Funding: The study was funded by the Economic and Social Research Council (RES-153-25-0101) through the ESRC Public Services Programme Third Call. The ESRC was not involved in data collection, analysis, or interpretation or in writing this manuscript.

Competing interests: All authors have completed the Unified Competing Interest form at www.icmje.org/coi_disclosure.pdf (available on request from the corresponding author) and declare that they have no nonfinancial interests that may be relevant to the submitted work.
6 Allan H, Larsen JA, Bryan K, Smith P. The social reproduction of institutional racism: internationally recruited nurses' experiences of the British Health Service. Diversity Health Social Care 2004;1:117-26.

7 Mahajan J, Stark P. Barriers to education of overseas doctors in paediatrics: a qualitative study in South Yorkshire. Arch Dis Child 2007;92:219-23.

8 Lambert TW, Goldacre MJ, Vallance E, Mallick N. Characteristics of consultants who hold distinction awards in England and Wales: database analysis with particular reference to sex and ethnicity. BMJ 2004;328:1347.

9 McManus IC, Esmail A, Demetrious M. Factors affecting the likelihood of applicants being offered a place in medical schools in the United Kingdom in 1996 and 1997: retrospective study. BMJ 1998;317:1111-7.

10 Cooke L, Halford S, Leonard P. Racism in the medical profession: the experience of UK graduates. British Medical Association, 2003.

11 Esmail A, Abel P, Everington S. Discrimination in the discretionary points award scheme: comparison of white with non-white consultants and men with women. BMJ 2003;326:687-8.

12 BMA Central Consultants and Specialists Committee. Tackling racism in medical careers: the role of consultants. British Medical Association, 2005.

13 Roberts JH, Sanders T, Wass V. Students' perceptions or race, ethnicity and culture at two UK medical schools: a qualitative study. Med Educ 2008;42:45-52.

14 Department of Health. On the state of the public health: annual report of the Chief Medical Officer. DH, 2007.

15 Woolf K, Cave J, Greenhalgh T, Dacre J. Ethnic stereotypes and the qualitative study. BMJ 2008;337:a1220.

16 General Medical Council. Good medical practice. GMC, 2010

17 Esmail A, Everington S. Complaints may reflect racism. BM 1994;208:1374.

18 Allen I. The handling of complaints by the GMC: a study of decisionmaking outcomes. Policy Studies Institute, 2000.

19 Kyriakides C, Virdee S. Migrant labour, racism and the British National Health Service. Ethn Health 2003;8:283-305.

20 Esmail A, Abel P. The impact of ethnicity and diversity on doctors performance and appraisal. Br J Health Care Manage 2006;12:303-7.

21 General Medical Council. Ethnicity: FTP fact sheet 2009. GMC, 2009.

22 Secretary of State for Health. Trust, assurance and safety-the regulation of health professionals in the 21st century. Stationery Office, 2007.

23 NHS Information Centre. NHS staff 1999-2009 (medical and dental). NHS Information Centre, 2010.

24 General Medical Council. Primary medical qualification: FTP fact sheet 2009. GMC, 2009.

25 National Clinical Assessment Service. NCAS casework: the first eight years. National Patient Safety Agency, 2009.

Accepted: 01 February 2011 underachievement of UK medical students from ethnic minorities: 